\title{
NUTRACEUTICALS AND FUNCTIONAL FOODS, A STRATEGY TO EMPOWER WOMEN'S HEALTH
}

\section{Neevitha Arunprabhu*}

RASS Academy College of Nursing, Sivagangai, Tamilnadu,

Received - July 18, 2020; Revision - September 17, 2020; Accepted - January 03, 2021

Available Online - March 25, 2021

DOI: http://dx.doi.org/10.18006/2021.9(Spl-1-GCSGD_2020).S49.S54

\section{KEYWORDS \\ Chemoprevention \\ Nutraceuticals \\ Functional foods \\ Sustainable health \\ Biodiversity}

\begin{abstract}
While healthy, balanced, and natural food meets the nutritional requirements of any healthy person, there are people, particularly women who need to be provided with supplements. Pregnant and lactating women, those with pre and post-menopause issues, and women with special dietary needs like sportswomen, models, etc., fall in this category. There is also a major issue of malnutrition endemic among a vast section of the society which, on account of the prevalent social mores and practices, impacts women more profoundly than the menfolk. On account of various sociological and economic factors, the special nutritional needs of women cannot be properly addressed through the normal consumption habits and nutraceuticals come as an effective solution to address this issue. Though not acknowledged to the extent it deserves, the nutraceuticals do play a decisive role in combating many life-threatening diseases like Cardio Vascular Diseases, Obesity, Hypertension, Arthritis, etc., both as an effective prophylactic as well as a curative aid to the mainline treatment. Known benefits of a carefully calibrated regimen of nutraceuticals are general performance enhancement, stress relief, increase in memory, immunity boosting, etc., Considering that women shoulder more than their share of family responsibility, women stand to be the main beneficiaries of such a health regimen, and in this sense, the nutraceuticals contribute to a considerable extent to the empowerment of women.
\end{abstract}

* Corresponding author

E-mail: nividasurendran@gmail.com (Neevitha Arunprabhu)

Peer review under responsibility of Journal of Experimental Biology and Agricultural Sciences.

Production and Hosting by Horizon Publisher India [HPI] (http://www.horizonpublisherindia.in/).

All rights reserved.
All the articles published by Journal of Experimental Biology and Agricultural Sciences are licensed under a Creative Commons Attribution-NonCommercial 4.0 International License Based on a work at www.jebas.org.

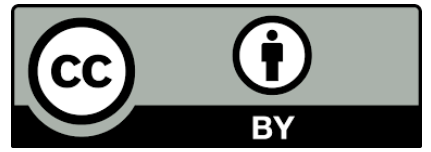




\section{Introduction}

Women's health is a major concern in any society for several reasons. Women who constitute nearly half the population, during their life cycle, undergo many physiological changes that call for special attention to them not only in terms of medical care but also of nutritional requirements. But the fact of the matter is that a large section of the women population only has a secondary claim on the family resources mainly because their immense contribution to the economic activities goes unrecognized. Consequently, their deprivation level in terms of nutritional food is worse than that of men seriously impacting their health. Hence there is a strong case for various nutraceuticals or functional foods to fill the gap in nutrition and thus contribute to improving women's health and thereby empower them.

The other aspect of Women's Health focuses on the treatment and diagnosis of diseases and conditions that affect a woman's physical and emotional wellbeing and here also nutraceuticals have a major role to play. Nutraceutical as a food or part of a food that provides medical or health benefits which includes the prevention and treatment of disease (Bull et al., 2000). Functional foods have a potentially positive effect on health beyond basic nutrition (Zeratsky, 2018).

Apart from the adoption of preventive measures against diseases and malnutrition, a special drive to provide for instant nutrition by sustained awareness drive with special reference to functional foods and nutraceuticals is the need of the day. The potential health benefits of functional foods and nutraceuticals in fortifying women's health is too immense to be ignored. Goldberg (1994) specified that functional foods are any food with its positive impact on an individual's health, physical performance, or state of mind in addition to its nutritive values. The three basic conditions of functional foods to have functional health benefits such as follows:

- Presence of natural ingredients in the food

- Should be capable of adoption as part of the daily diet

- Should be able to regulate a particular body process, such as :

a. Enhancement of the biological defense mechanism

b. Prevention of a specific disease

c. Recovery from a specific disease

d. Control of physical and mental conditions

e. Slowing the aging process

Nutraceuticals typically include food products like dietary fiber, prebiotics, probiotics, polyunsaturated fatty acids, antioxidants, and other different types of herbal /natural foods (Das et al., 2012). Women are identified as one of the most important consumer groups for functional foods as they need to face specific health issues and meet the nutritional needs during pregnancy, the postpartum period, and menopause (Carabin, 2006). This review study emphasizes the importance of women's health with a report on various review articles based on functional foods and Nutraceuticals. It is intended to create better awareness among women on the efficacy of various food products and the different options available for them to meet their specific requirements and thus help them become wise consumers.

This review paper summarizes the specific needs of women and the properties of functional foods and Nutraceuticals to reduce the risk of various diseases. The current research works and scientific evidence found available in recent journals and review articles provide data to analyze and understand the health benefits of functional foods for women. The main objective of the present paper is to impart nutrition education for women and encourage future studies on functional foods and Nutraceuticals.

\section{Empathy: Health Promotion for Women}

The process of health promotion enables people to improve their health and thus lead a more fulfilling life as part of the empowering process. The positive measures to strengthen women may suggest the following approaches:

\subsection{Recommendation for healthy living}

While addressing the specific health and fitness at different stages of women's life, we need to adopt healthy living by

- Planning a healthy diet( with fruits and vegetables, foods low in saturated and trans fats)

- Regular exercises

- Maintenance of healthy body weight

- Avoiding alcohol and smoking

People who are more physically active, with improved lifestyle changes can focus on the right energy balance and lead a healthy living (Nandakumar \& Swarajyalakshmi, 2010).

\subsection{Identification of vulnerable group}

Nearly $85 \%$ of menstruating women (between the age group of 2040 years) are experiencing one or more symptoms of Pre Menstrual Syndrome (PMS). The major symptoms of PMS which last for almost two weeks include mental and physical responses to hormonal imbalances (Alliance Integrative Medicine, 2020). Women at home are likely to suffer from overeating and hence they are subject to the risk of becoming overweight. Meal planning with less food wastage can avoid the consequences of "left-overs" (Anderson, 1985). The natural and preventive approach of women to manage the physiological changes and challenges identifies Nutraceuticals as a valuable tool in promoting better health (Olivo, 2016). 


\subsection{Concern on risk factors}

Overweight women are particularly susceptible to cancer of the uterus, gallbladder, ovary, and breast (Antia \& Abraham, 2005). Lack of motivation and enthusiasm prevents women from maintaining healthy body weight. But the combination of a sensible diet and regular exercise can help tackle the issue of overweight (Jindal, 2015). Women are unaware that micronutrient deficiencies can persist for an extended period in their life and need to be accordingly taken care of by proper nutrition supplements. The majority of the female population is susceptible to diseases such as anemia, osteoporosis, obesity, and depression during post menopause stage (Akkawi \& Zmerly, 2018).

The secondary metabolites of functional foods and the cumulative effect of several components of Nutraceuticals may aid in the prevention and treatment of various diseases
Anemia among arthritic patients due to disease conditions as well as improper iron absorption results in women suffering more severe illness than men (Damle, 2005).

Women tend to have smaller and lighter bones than men. The low bone mass and menopause affect their bone health; this may lead to an increased risk of developing osteoporosis (Halvorsen, 2016). Table 1 lists the health benefits of various functional foods and Nutraceuticals for women indicating the area of their utility (Aoi et al., 2006; Rudkowska, 2008; Iron deficiency occurs in women due to inadequate intake of iron-rich foods. Moreover, menstruation increases the risk of having low body stores of iron (The Irish Nutrition \& Dietetic Institute, 2015). Women are more prone to Urinary Tract Infections (UTI) during pregnancy and after menopause. About $50 \%$ of the women population develops at least one UTI during their lifetime (Naveen, 2011).

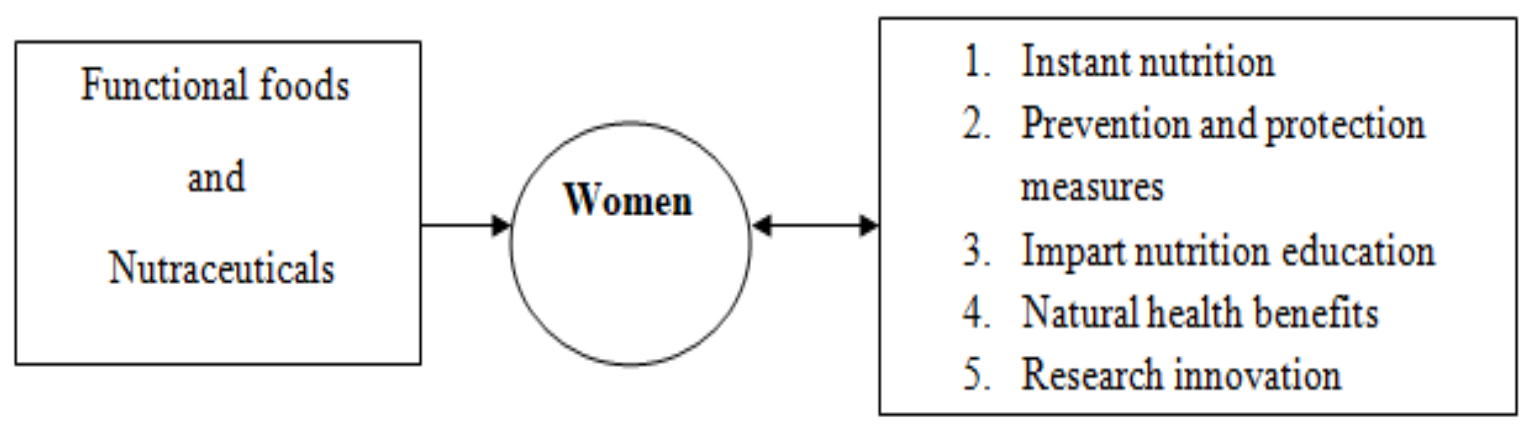

Figure 1 Schematic representation of functional foods and Nutraceuticals for women

\section{Strategy: Functional foods and Nutraceuticals for Women}

Any strategy to improve general health by necessity has to target women. Such an approach encourages them to consume highly fortified nutritional and functional snacks (Sloan, 2018).

It is advisable to gain nutritional knowledge about functional foods through gym instructors and nutritionists (Kapoor \& Munjal, 2017). Figure 1 shows a schematic representation of Functional Foods and Nutraceuticals for women illustrating the strategy for improving women's health status.

Most of the degenerative types of arthritis like osteoarthritis, osteoporosis, and lumbar spondylitis intensify with weight gain. Sustainable health can be defined as "healthy and active aging avoiding the risk of diseases". Functional food markets with their products can contribute to sustainable health by protecting and improving public health (DelCastillo et al., 2018).
- Pomegranate Juice

- Citrus Fruits

- Avocado Milkshakes

- Berries And Cherries

- Tofu

- Sprouts

- Dates

- Almonds

- Milk And Its Products Like Yoghurt, Paneer

- Oats And Other Fortified Cereals

- Green Leafy Vegetables

4 Technology: Bioactive compounds and Biodiversity for Women

various illnesses. Chemoprevention uses natural or synthetic agents to reverse the process of carcinogenesis. Regular consumption of dietary phytochemicals for chemoprevention serves as an economical alternative to control cancer. Similarly, phenolic 
compounds reduce the risk of cancer. Phytochemicals have a role in the regulation of body metabolism by

- Enhancing nutrient absorption

- Eliminating toxins

- Inhibiting the growth of harmful intestinal bacteria (Helal, 2019).

The polyphenols present in fruits, cereals, and vegetables are proven to be effective antimutagenic, anticarcinogenic, and antioxidants (Souyoul, 2018). Bioactive compounds are extra nutritional constituents present in small quantities in foods (Teodoro, 2019). The phenolics compounds of fruit residues like grape seed extract, anthocyanins of litchi pericarp, flavonoids in citrus peels, antioxidants of mango peels and stones provide a lot of scopes for exploring the therapeutic potential of Nutraceuticals by implementing low cost waste technology in agribusiness (Babbar et al., 2013).
The therapeutic capability, potential nutrients, and safety profile of nutraceuticals may be used to improve health, delay the aging process and prevent chronic diseases (Nasri et al., 2014). Any scheme aimed at making available essential nutrients including nutraceuticals and functional foods to all those who need them should have as part of its strategy the following components:

- Biodiversity/Conservation measures to ensure that there is no shortage in the supply of these vital health inputs.

- Sustained awareness drive focusing on the prevalence of poverty, malnutrition, and hunger and the measures required to be undertaken at all levels to overcome them.

- The 2030 agenda for sustainable development is achieved by dovetailing various local developmental activities to the former.

- Research and Development in the area of harnessing the biological significance of active chemical components of food by the rapid analytical methods.

Table 1 Health benefits of functional foods and Nutraceuticals for women

\begin{tabular}{|c|c|c|}
\hline Functional Foods and Nutraceuticals & Properties & Reduces risk of \\
\hline $\begin{array}{ll}\text { - } & \text { Soy proteins and isoflavones } \\
\text { - } & \text { Omega } 3 \text { fatty acids } \\
\text { - } & \text { Plant sterols } \\
\text { - } & \text { Prebiotics and probiotics } \\
\text { - } & \text { Fiber-rich foods } \\
\text { - } & \text { Colored fruits } \\
\text { - } & \text { Pumpkin Seeds, Flax seeds, } \\
\text { - } & \text { Avocado } \\
\text { - } & \text { Sweet potatoes } \\
\text { - } & \text { Calcium, Iron, and Magnesium- } \\
& \text { rich foods }\end{array}$ & $\begin{array}{ll}\text { - } & \text { Anti-inflammatory } \\
\text { - } & \text { Anti-oxidant } \\
\text { - } & \text { Immune modulation } \\
\text { - } & \text { enhances muscle strength } \\
\text { - } & \text { reduces lipid levels } \\
\text { - } & \text { improves bone health } \\
\text { - } & \text { increases memory } \\
\text { - } & \text { Anti-carcinogenic } \\
\text { - } & \text { Antimicrobial }\end{array}$ & $\begin{array}{ll}\text { - } & \text { Cardio Vascular Diseases } \\
\text { - } & \text { Diabetes } \\
\text { - } & \text { Obesity } \\
\text { - } & \text { Hypertension } \\
\text { - } & \text { Arthritis } \\
\text { - } & \text { Cancer } \\
\text { - } & \text { PMS } \\
\text { - } & \text { UTI }\end{array}$ \\
\hline
\end{tabular}

\section{Discussions}

Functional Foods and Nutraceuticals with their significant health benefits enrich women's health in all the stages of life and significantly contribute to an enhanced quality of life. Though there is a growing case to support even more extensive use of functional foods and Nutraceuticals, there is also a need to carry out more research in understanding their mechanism on our body, especially of women. The health status of women can be improved with immune boosters, natural energizers, and antioxidants. However, the conflicting results on the effect of antiestrogenic soy isoflavones, additional techniques for vitamin $\mathrm{D}$, and calcium absorption (fortification) are some of the areas which are crying for immediate resolution. Poor bioavailability of some essential nutrients and the low level of active ingredients in some of them poses a challenge of an altogether different kind.

\section{Conclusion}

Functional foods and Nutraceuticals play a central role in the fortification of women's health both as food supplements and therapeutic inputs. There is a need to devise a sustained action plan 
that focuses on all essential areas like research, awareness, marketing, and accessibility. The important link is to make sure that women are integrated into the program of social welfare and community development that focuses on practical skills that make them aware of their own needs and responsibilities.

Making better women with good nutritional status and supportive health care at all stages of life is an essential but not necessarily an easy task. Recent studies on functional foods and Nutraceuticals have concentrated on encouraging women to improve nutritional knowledge. This helps in the maintenance of normal wellbeing by reducing the risks of various disease conditions.

The study on biological properties of fruit residues such as anticarcinogenic, antimutagenicity, and antiaging activity has opened new vistas in the area of the development of high-quality food products. Simple dietary advice by a qualified nutritionist for the consumption of functional foods and Nutraceuticals can be a gamechanger in transforming women's health. This paper can serve as a survey article for students to pursue their research.

\section{Acknowledgments}

I extend my sincere thanks to my teachers Dr. R.Latha, Dr Vasantha Esther Rani, and Dr.Sr.Mary of Home science Department, Fatima College, Madurai. My special thanks to Dr.Anto Cordelia Tanislaus Antony Dhanapal, University Tunku Abdul Rahman, Malaysia. I extend my heartfelt thanks to Mr. A. Chandrashekhar Kunigally, Ex Deputy Director General at Government of India who gave me constant support for editing the manuscript. I thank my friend Amuthavalli Sathish Pandian for her encouragement and positive spirit. I extend my thanks to Mrs.S.Jeyaselvi for her supportive guidelines to learn functional foods and nutraceuticals. I'm fortunate to have you, Arunprabhu!

\section{References}

Akkawi I, Zmerly H (2018) Osteoporosis: Current Concepts. Joint 6(2): 122. DOI: 10.1055/s-0038-1660790.

Alliance Integrative Medicine (2020) Managing Diet to Manage Your PMS. https://myhealingpartner.com/managing-diet-managepms/, retrieved on 09 February 2020.

Anderson CR (1985) Your Guide to Health. Oriental Watchman Publishing House, Pune: 71.

Antia FP, Abraham P (2005) Clinical Dietetics and Nutrition. Oxford University Press, New Delhi: 338.

Aoi W, Naito Y, Yoshikawa T (2006) Exercise and Functional Foods. Nutrition Journal. https://doi.org/10.1186/1475-2891-5-15, retrieved on 07 February 2020.
Babbar N, Oberoi HS, Sandhu SK (2013) Therapeutic and Nutraceutical Potential of Bioactive Compounds Extracted from Fruit Residues. Critical Reviews in Food Science and Nutrition, 55(3). DOI: 10.1080/10408398.2011.653734.

Bull E, Rapport L, Lockwood B (2000) What is a nutraceutical?. The Pharmaceutical Journal online, 265:57. https://www.pharmaceutical-journal.com/download?ac=1064856, retrieved on 20 June 2020.

Carabin IG (2006) Women's Health and Functional Foods. http://burdockgroup.com/womens-health-and-functional-foods/, retrieved on 06 February 2020.

Damle L (2005) Arthritis-meticulous care bears. Heritage Amruth, Special Issue, Medplan Conservatory Society, Bangalore: 60.

Das L, Bhaumik E, Raychaudhuri U, Chakraborty R (2012) Role of Nutraceuticals in Human Health. Journal of Food Science and Technology 49(2): 173-183.DOI: 10.1007/s13197-011-0269-4, retrieved on 09 July 2020.

Del Castillo MD, Iriondo-DeHond A, Martirosyan DM (2018) Are Functional Foods Essential For Sustainable Health?. Annals of Nutrition and Food Science, 2(1): 1015.https://pdfs.semanticscholar.org/2dff/d1dd1593943cc38d4db 14df4bad2f8c82bcc.pdf, retrieved on 06 February 2020.

Ganapathy M, Bhunia S (2016) Nutraceuticals: The New Generation Therapeutics. Advanced Techniques in Biology and Medicine, 4(2):1-5. http://dx.doi.org/10.4172/2379-1764.1000179, retrieved on 10 February 2020.

Goldberg I (1994) Designer foods, Pharma foods and Nutraceuticals. In: Goldberg I (Ed.), Functional Foods, Springer Science +Business Media Dordrecht, Springer US.DOI: 10.1007/978-1-4615-2073-3, retrieved on 09 July 2020.

Halvorsen R (2016) Osteoporosis: Why It Affects More Women than Men. https://www.aurorahealthcare.org/patientsvisitors/blog/osteoporosis-why-it-affects-more-women-than-men, retrieved on 11 June 2020

Helal N, Eassa HA, Amer AM, Eltokhy MA, Edafiogho I, Nounou MI (2018) Nutraceuticals' Novel Formulations: The Good, the Bad, the Unknown and Patents Involved. Recent Patents on Drug Delivery Formula, 13(2):105156.DOI: 10.2174/1872211313666190503112040, retrieved on 05 January 2021.

Jindal SR (2015) Nutrition and Health: The Vegetarian Way. Sterling Publishers Private Limited, New Delhi: 71, 72.

Kapoor D, Munjal A (2017) Functional Foods: The New Secret of the Health Conscious Indian Women. https://journals.sagepub.com/doi/10.1177/0972150917692196, retrieved on 06 February 2020. 


\section{Nutraceuticals and Functional Foods, a Strategy to Empower Women's Health}

Kumar R, Bhayana S, Kapoor S (2015) The Role of Functional Foods for Healthy Life: Current Perspectives. International Journal of Pharma and Bio Sciences, 6(3):429-433. https://www.researchgate.net/publication/282223278_The_role_of _functional_foods_for_healthy_life_Current_perspectives retrieved on 06 February 2020.

Nandakumar B, Swarajyalakshmi (2010) Women's Health Problems. Jindal Naturecure Institute Publications, Bangalore: 5, 35,193 .

Nasri H, Baradaran A, Shirzad H, Rafieian-Kopaei M (2014)New Concepts in Nutraceuticals as Alternative for Pharmaceuticals. International Journal of Preventive Medicine, 5(12):1487.https://www.ncbi.nlm.nih.gov/pmc/articles/PMC43369 79/, retrieved on 05 January 2021.

Naveen S (2011) Getting rid of UTIs. Heritage Amruth, 7(4): 13.

Olivo L (2016) Nutraceuticals World: Fortifying Women's Health. https://www.nutraceuticalsworld.com/issues/2016-

05/view_features/fortifying-womens-health/, retrieved on 09 February 2020.

Rudkowska I (2008) Functional Foods for Cardiovascular Disease in Women. Menopause International, 14(2):63-69. https://doi.org/10.1258/MI.2008.008002, retrieved on 10 February 2020.
Sloan E (2018) Top Ten Functional

Food

Trends.https://www.ift.org/news-and-publications/food-

technology-magazine/issues/2018/april/features/top-10-functionalfood-trends-2018, retrieved on 06 February 2020.

Souyoul SA, Saussy KP, Lupo MP (2018) Nutraceuticals: A Review. Dermatology and Therapy, 8:5-16. https://doi.org/10.1007/s13555-018-0221-x, retrieved on 05 January 2021.

Teodoro AJ (2019) Bioactive Compounds of Food: Their Role in the Prevention and Treatment of Diseases. Oxidative Medicine and Cellular Longevity, 2019:1-4. https://doi.org/10.1155/2019/3765986, retrieved on 09 February 2020.

The Irish Nutrition and Dietetic Institute (2015) Women and Iron: Women's Health. https://indi.ie/women-s-health/546-women-andiron.html, retrieved on 11 June 2020.

Zeratsky K (2018) Nutrition and Healthy eating. https://www.mayoclinic.org/healthy-lifestyle/nutrition-andhealthy-eating/expert-answers/functional-foods/faq-20057816, retrieved on 20 June 2020. 